\title{
Isolation and Characterization of Rhizobium from Chickpea (Cicer arietinum)
}

\author{
Zeenat Wadhwa ${ }^{1}$, Vivek Srivastava ${ }^{2}$, Raj Rani ${ }^{1}$, Tanvi ${ }^{1}$, \\ Kanchan Makkar ${ }^{1}$ and Sumit Jangra ${ }^{3 *}$ \\ ${ }^{1}$ Department of Biotechnology, Dayanand College, Hisar-125001, Haryana, India \\ ${ }^{2}$ Department of Botany, Dayanand College, Hisar-125001, Haryana, India \\ ${ }^{3}$ Department of Molecular Biology, Biotechnology and Bioinformatics, CCS Haryana \\ Agricultural University, Hisar-125004, Haryana, India \\ *Corresponding author
}

\section{A B S T R A C T}

\begin{tabular}{|l|}
\hline Ke y w or d s \\
YEMA, Congo red, \\
Chickpea, Rhizobia, \\
Legumes and bacteria.
\end{tabular}

Nutrient paucity in the soil poses confront to global production of food. The use of synthetic nitrogen fertilizers to boost crop yield is a recurrent farming practice, despite of its unfavorable effects and hazard to the environment and human population. Rhizobium is gram negative bacterium which associates symbiotically with the roots of leguminous plants. Screening and selecting the rhizobial strain is important for biological nitrogen fixation. The present study was aimed to isolate and identify Rhizobium from Cicer arietinum (chickpea) root nodules by using CRYEMA medium. The result indicated that a bacterium from root nodules of chickpea does not absorb red color on YEMA medium and the milky white colony with spherical convex surface was isolated. Many biochemical tests of the isolated strain like oxidase, catalase and bromothymol blue were positive, while starch hydrolysis, lipase test, lysine decarboxylase and caseinase were negative which revealed that the strain isolated from chickpea plant belongs to Rhizobia species. The study indicated that all the strains grew well at $\mathrm{pH} 6$ and 7 , temperature $28^{\circ} \mathrm{C}$ to $30^{\circ} \mathrm{C}$ and at salt concentration of $1 \%$. The strains showed resistance to the antibiotics, metal salts and salinity.

\section{Introduction}

With increased concern about the production of adequate amount of food to feed the constantly increasing human population which is going to touch a mark of 9 billion by 2050 has forced us to reinforce the importance of sustainable increase in crop productivity. One of the methods for sustainable agricultural includes the use of beneficial microorganisms for plants as they are able to promote plant growth by growing endophytically on plants, in symbiotic association with plants or as free-living cells in soil. The requirement for good agricultural practices is revitalizing the interest in biological nitrogen fixation and Rhizobialegumes symbiosis, particularly those involving economically important legume crops in terms of food and forage.

Legumes are agronomically and ecologically important symbionts that lead to the development of new plant organ (legume nodule) in response to nitrogen fixing bacteria (Datta et al., 2015). In developing countries 
like India and other South Asian countries, chickpea is an important source of protein for millions of people. Other than having high protein content (20-22\%), chickpea is rich in fiber, minerals (phosphorus, calcium, magnesium, iron and zinc) $\beta$-carotene and large amount of unsaturated fatty acids (Gaur, 2010). Besides playing an important role in human diet it also improves soil fertility by fixing the atmospheric nitrogen (Siddiqi and Mahmood, 2001; Kantar et al., 2007). Maximum nitrogen requirement (4-85\%) of chickpea as a legume is obtained through symbiotic Nitrogen fixation in association with compatible Rhizobium strain (Chemining and Vessey, 2006). The genus Mesorhizobium includes species with high geographical dispersion and able to nodulate a wide variety of legumes, including important crop species, like chickpea. It has been estimated that $1 \mathrm{~g}$ of soil may contain a community of $10^{9}$ microorganisms with Rhizobia representing around $0.1 \%$ of soil microbes or $10^{6} \mathrm{~g}^{-1}$ soil.

Rhizobia are one of the most efficient bacterial symbionts of legumes that fix atmospheric nitrogen by the process of biological nitrogen fixation (BNF).

Rhizobia are able to metabolize atmospheric nitrogen and convert it into plant usable form in specialized structures called nodules where aerobic condition are maintained by leghaemoglobin. In return, Rhizobia utilize the carbon substrates derived from the plant photosynthesis. In agriculture, perhaps $80 \%$ of the biologically fixed nitrogen comes from symbiosis involving leguminous plants and bacteria of family Rhizobiaceae.

The biological nitrogen fixation because of Rhizobia-legume symbiosis benefits not only the host crop but also the subsequent crops in that field. Besides this, it may also act as a non-symbiotic PGPB as in the case of certain non-legume crops such as rice or wheat, which are the best-studied examples that benefit from Rhizobia as endophytes (Biswas et al., 2000). For all these reasons, the Rhizobium-legume symbiosis has been widely studied as a model of mutualistic associations and as a beneficial association for sustainable agriculture. With increasing use of Rhizobium and other beneficial microbes as bio fertilizers, reduction in the need for chemical fertilizers can be observed. Therefore, bio fertilization has great importance in decreasing environmental pollution and deterioration of nature (Vessey, 2006; Erman et al., 2011). The inoculation of seeds with Rhizobium is known to increase nodulation, $\mathrm{N}$ uptake, growth and yield parameters of legume crops (Erman et al., 2011). Keeping in view the importance of Rhizobia in legume plants, the present study was undertaken to shed some light on different morphophysiological and biochemical properties of Rhizobial strain isolated from chickpea plant.

\section{Materials and Methods}

\section{Collection and extraction of root nodules from the chickpea plants}

The experimental material for the present study was collected from Hisar district. Plants possessing healthy nodules with pink color were selected and transported to the lab (Fig. 1). Root nodules of chickpea plant (Cicer arietinum) were used as study material for isolation and further morphological and physiological characterization of Rhizobium strain. The roots were first washed thoroughly with sterile distilled water and nodules were surface sterilized by washing with $95 \%$ ethanol for 10 seconds and again washed in sterile distilled water for about 5 times. Roots were mashed with pestle mortar to obtained nodules and milky white substances of bacteroids by dipping in phosphate buffer solution. 
Serial dilutions of the extracted root nodules

After the extraction of bacteroid solution from the chickpea root nodules, serial dilution was made. $2 \mathrm{ml}$ of sterilized root nodule bacteroids solution was taken in $90 \mathrm{ml}$ sterilized distilled water and serially diluted up to $10^{-6}$ dilution. For identification of the colonies, $10^{-4}$ to $10^{-6}$ dilution of nodule extract were plated on YEMA Congo red agar media plates. The petri plates were then kept in the incubator at $37{ }^{\circ} \mathrm{C}$ for 3 days. After the plates were taken out of the incubator colony morphology and identification was carried out. All bacteriological isolation and the entire process of biochemical tests were carried in the laminar airflow to maintain the sterility.

\section{Gram staining of the bacterial strain}

The pure cultures of bacterial strains were put for gram staining for more specific identification of the colonies. The gram staining was done in laminar air flow hood.

The slides were firstly washed with ethanol and colonies were marked on the slides with the help of inoculating needle and were heat fixed. Then smears were stained in following steps a) First applied crystal violet on each slide and kept for $1 \mathrm{~min}$. b) Distilled water wash. c) Iodine on the slides as mordant (1 min) then $95 \%$ alcohol wash $(30 \mathrm{sec}$.) and then washed with distilled water. d) Safranin was applied on the slides and then washed with distilled water and f) air dried the slides. The entire gram staining technique was done following the Christian Gram technique and Collee JG, Miles RS Mackie (1989).

\section{Effect of salt}

The salinity tolerance was assessed by culturing the bacteria on YEMA medium containing different salt concentration $1 \%$, $2 \%, 3 \%, 4 \%(\mathrm{w} / \mathrm{v}) \mathrm{NaCl}$.

\section{pH variation assay}

The ability of Rhizobial isolate to grow at different $\mathrm{pH}$ was tested in YEMA medium by adjusting the $\mathrm{pH}$ to 5.0, 6.0, 7.0, 8.0 and 9.0 with $\mathrm{NaOH}$ and $\mathrm{HCl}$.

\section{Temperature tolerance}

Temperature Tolerance was investigated by assaying the growth of bacterial cultures in YEMA medium at different temperature viz. $5^{\circ} \mathrm{C}, 28^{\circ} \mathrm{C}, 35^{\circ} \mathrm{C}$ and $40^{\circ} \mathrm{C}$.

\section{Effect of metal salts}

The isolate was tested for their sensitivity to metal by amendment of freshly prepared YEMA plates with metal salts i.e. $\mathrm{HgCl}_{2}$ and $\mathrm{ZnSO}_{4}$ at $1 \%(\mathrm{w} / \mathrm{v})$ concentration. Effect of metal salts was determined by assaying Rhizobial growth after incubating the plates at $30^{\circ} \mathrm{C}$ for 48 hours.

\section{Intrinsic Antibiotic Resistance (IAR) spectra}

IAR was carried out to identify sensitivity or resistance of Rhizobia strain to different antibiotics. Antibiotics discs were used to assay the antibiotic resistance on YEMA media containing bacterial culture evenly spread across the surface. Petri plates containing the disc were incubated at $30{ }^{\circ} \mathrm{C}$ for 3-7 days.

The presence or absence of inhibition zones around different antibiotics discs was noted (Bauer et al., 1966). Filter paper discs containing different antibiotics viz. kanamycin, vancomycin, chloramphenicol and gentamycin were used in the present study. 


\section{Biochemical studies}

\section{Catalase test}

This test was performed to study the presence of enzyme catalase in Mesorhizobium spp which hydrolyzes $\mathrm{H}_{2} \mathrm{O}_{2}$ into $\mathrm{H}_{2} \mathrm{O}$ and $\mathrm{O}_{2}$ in bacterial strains. Firstly, smear of strain was made on a clean and dry glass slide, then a few drops of $\mathrm{H}_{2} \mathrm{O}_{2}$ were added to the slide. Production of gas bubbles and effervescence showed a positive test.

\section{Citrate utilization test}

Citrate utilization as a carbon source was examined by adding sodium citrate and Bromothymol blue $(25 \mathrm{mg} / \mathrm{l})$ instead of mannitol in YEM agar medium. Isolates of Mesorhizobium spp. were streaked in sodium citrate added YEMA medium plates with bromothymol blue as an indicator. Thenplates were incubated for 24 - 48 hours.

\section{Bromothymol blue test}

It selectively identifies fast and slow growing isolate of Rhizobium. For this test, bacteria were inoculated on YEM agar medium containing $0.025 \%$ bromothymol blue and incubated for 3 to 10 days for acid or alkaline reaction ${ }^{[32]}$. In this test sample were allowed to grow YEM media contains BTB. After incubation for 48 hours at $28^{\circ} \mathrm{C}$ positive sample showed yellow color due to acid production

\section{Lipase test}

Lipase presence around bacterial colonies was detected by supplementing YEM with $1 \%$ (w/v) Tween 80.

\section{Oxidase test}

Oxidase test was performed to determine the presence of oxidase enzyme in different isolates of Mesorhizobium spp. Kovac's reagent $(1 \% \mathrm{~N}, \mathrm{~N}, \mathrm{~N} . \mathrm{N}$-tetramethyl-phenylene diamine) was dissolved in warm water and stored in dark bottle. A strip of filter paper was dipped in this reagent and air-dried and put into one-day-old Rhizobial colonies from agar plates.

\section{Starch hydrolysis}

This test was performed to determine the capability of Rhizobium to use starch as a carbon source. For starch utilization Starch Agar Medium was inoculated with Rhizobium then iodine was added to determine the capability of microbes to use starch. A drop of iodine $(0.1 \mathrm{~N})$ was spread on 24 hours old culture that showed clear zone of inhibition around bacterial colonies.

\section{Lysine decarboxylase test}

In this test Rhizobium strains were streaked on Bromocresol Purple Falkow medium (peptone $5 \mathrm{~g}$, yeast extract $3 \mathrm{~g}$, glucose $1 \mathrm{~g}$, Bromocresol purple $0.02 \mathrm{~g}$, distilled water 1 liter). Then Rhizobial strains were streaked on the media and were kept for incubation at 34 ${ }^{0} \mathrm{C}$ for 24 hours.

\section{Results and Discussion}

\section{Morphological characteristics}

On the basis of morphological characters, the isolates were circular in shape with entire margin and milky to watery translucent appearance on CRYEMA medium. It was found that the strain grown showed the convex elevation in Yeast Extract Mannitol Agar medium. The colonies were $2.5 \mathrm{~mm}$, translucent, whitish pink and glittering (Fig. 2). Roychowdhury et al., (2015) showed the growth of Rhizobium bacteria on Congo red Yeast Extract Mannitol agar medium. Rhizobial isolates were tentatively assigned to genera Mesorhizobium on the basis of 
morphological characters. Similarly, Rai et al., (2013) and Gauri et al., (2012) also characterized mesorhizobial isolates on the basis of their colony shape, colour and texture. Datta et al., (2015) also found that Rhizobium was Gram negative, motile, rod shaped and were fast growers as they showed convex elevation in Yeast Extract Mannitol medium. Table 1 represents the morphological and cultural characteristics of strains indicating Rhizobium.

\section{Microscopic observations}

Gram's staining of the isolates was confirmed by microscopic observations and the Mesorhizobium spp. was found to be gram negative. Gauri et al., (2012) also reported that microscopic examination of Rhizobiumrevealed the isolates to be gram negative. Roychowdhury et al., (2015) observed his strain under the microscope by gram staining which showed white pinkish color and rod shaped bacteria.

\section{Effect of salt, $\mathrm{pH}$ and temperature on Rhizobium growth}

Symbiotic nitrogen fixation is restricted by many factors. One such factor is salinity as Rhizobium grows at higher salt levels as compared to their host plant species. Furthermore, chickpea is sensitive when it comes to salt tolerance and thus salinity is considered as one of the most important limiting factors for BNF of chickpea in arid and semiarid regions. Several studies conducted on chickpea (Singla and Garg, 2005; Garg and Singla, 2009) showed that $\mathrm{NaCl}$ salinity resulted in decreased plant growth, less N2 fixation, decreased nodule numbers and reduced percentage of tissue nitrogen. Whereas, Rhizobia isolated from chickpea nodules and are comparatively tolerant to salt than their host (Vanderlinde et $a l ., 2010)$. However, these bacteria differ in their capability of $\mathrm{NaCl}$ tolerance as some strains may grow at salt concentrations as high as $500 \mathrm{mM} \mathrm{NaCl}$, others may not grow even at low $\mathrm{NaCl}$ concentration $(100 \mathrm{mM})$ (Kucuk and Kivanc, 2008). In the present study, it was found that strain of rhizobia showed different growth rate at different concentration of $\mathrm{NaCl}$, maximum growth rate was observed at $1 \%(\mathrm{w} / \mathrm{v}) \mathrm{NaCl}$ and minimal at $4 \%(w / v) ~ \mathrm{NaCl}$ (Fig. 3; Fig. 9). Jida and Assefa (2012) also reported high tolerance to $\mathrm{NaCl}$ where $75 \%$ of the tested rhizobia could grow well with $1 \% \mathrm{NaCl}$. However, at higher concentrations, the percentage of tolerant isolate decreased with increasing salt concentration as only $11.1 \%$ of the isolates tolerated 5\% NaCl. Berrada et al., (2012) observed that $31 \%$ of the strains were tolerant to $2 \% \mathrm{NaCI}$ when grown at different $\mathrm{NaCl}$ concentrations $(0.5,1,1.5$, and $2 \%)$.

Temperature is one of the major factors affecting rhizobial growth, survival in the soil and the symbiotic process itself (Niste et al., 2013). High soil temperature in tropical regions is one of the major constraints for $\mathrm{BNF}$ in legume crops. High temperature may affect symbiotic relationships, nitrogen content, formation of roots, binding of rhizobia to root hairs, nodule development and function, and dry matter production (Boboye et al.,2011).Low temperature affects nodulation, as the process of nodule initiation is completely inhibited under low 13 temperature (Sadowsky, 2005). High temperature also alters the pattern of cell surface components (EPS and LPS) secreted by rhizobia, which in turn negatively affects the process of nodulation and $\mathrm{N}_{2}$ fixation Yadav et al., (2010).The optimum temperature for growth of root nodulating bacteria ranged from $25^{\circ} \mathrm{C}-30^{\circ} \mathrm{C}$, however in both saprophytic and symbiotic life rhizobia often encounter temperature variation. Isolates of rhizobia were grown in YEMA medium different temperature viz. $5^{\circ} \mathrm{C}, 28^{\circ} \mathrm{C}$, 
$35^{\circ} \mathrm{C}$ and $40^{\circ} \mathrm{C}$ for evaluating thermo tolerance. In the present study, optimum temperature for rhizobial growth was found to be $28^{\circ} \mathrm{C}$ whereas moderate growth was observed at $35^{\circ} \mathrm{C}$ and minimal growth of isolates was exhibited at $5^{\circ} \mathrm{C}$ and $40^{\circ} \mathrm{C}$ (Fig. 4). Alexandre et al., (2009) reported that temperature greatly affected the growth and symbiotic performance of Rhizobia. Maatallah et al., (2002) reported maximum growth of Mesorhizobia between 20 to $30{ }^{\circ} \mathrm{C}$.

To observe $\mathrm{pH}$ tolerance of the rhizobial isolates, they were grown in YEMA medium by adjusting $\mathrm{pH}$ to 5-9 and the plates were incubated at $28{ }^{\circ} \mathrm{C}$ for 36 hours. In the present study, optimum $\mathrm{pH}$ for rhizobial growth was between 6-7. Minimal growth of isolates was exhibited at $\mathrm{pH} 8$ and $\mathrm{pH} 9$ (Fig. 5).

Deora and Singhal, 2010 have proposed that slight variation in the $\mathrm{pH}$ of medium might have an enormous effect on the growth of Rhizobium. Rhizobial isolates were observed to be more sensitive to low $\mathrm{pH}$ than their host and this affects the establishment of the symbiosis, limiting the survival and persistence of the Rhizobia (Zahran, 1999).

Table.1 Morphological study of Rhizobial strain

\begin{tabular}{|c|l|l|}
\hline S. No. & Strain characteristic & Rhizobial strain \\
\hline 1 & Shape & Circular \\
\hline 2 & Size & $2.5 \mathrm{~mm}$ \\
\hline 3 & Color & White \\
\hline 4 & Opacity & Transparent \\
\hline 5 & Bacterium shape & Rod shaped \\
\hline 6 & Gram nature & Gram negative \\
\hline 7 & Motility & Mobile \\
\hline
\end{tabular}

Table.2 Effect of metal ions on growth of Rhizobia

\begin{tabular}{|c|c|}
\hline Metal Salt & Growth \\
\hline $\mathrm{HgCl}_{2}$ & - \\
\hline $\mathrm{ZnSO}_{4}$ & + \\
\hline
\end{tabular}

Growth is signified by "+" and poor growth is signified by"-.".

Table.3 Effect of various biochemical tests

\begin{tabular}{|c|c|c|}
\hline S.No. & Biochemical Test & Growth \\
\hline 1 & Bromothymol blue & + \\
\hline 2 & Caesinase & - \\
\hline 3 & Catalase & + \\
\hline 4 & Citrate & - \\
\hline 5 & Lipase & - \\
\hline 6 & Lysine decarboxylase & - \\
\hline 7 & Oxidase & + \\
\hline 8 & Starch hydrolysis & - \\
\hline
\end{tabular}

Growth is signified by "+" and poor growth is signified by "-". 
Fig.1 Chickpea plant root nodules

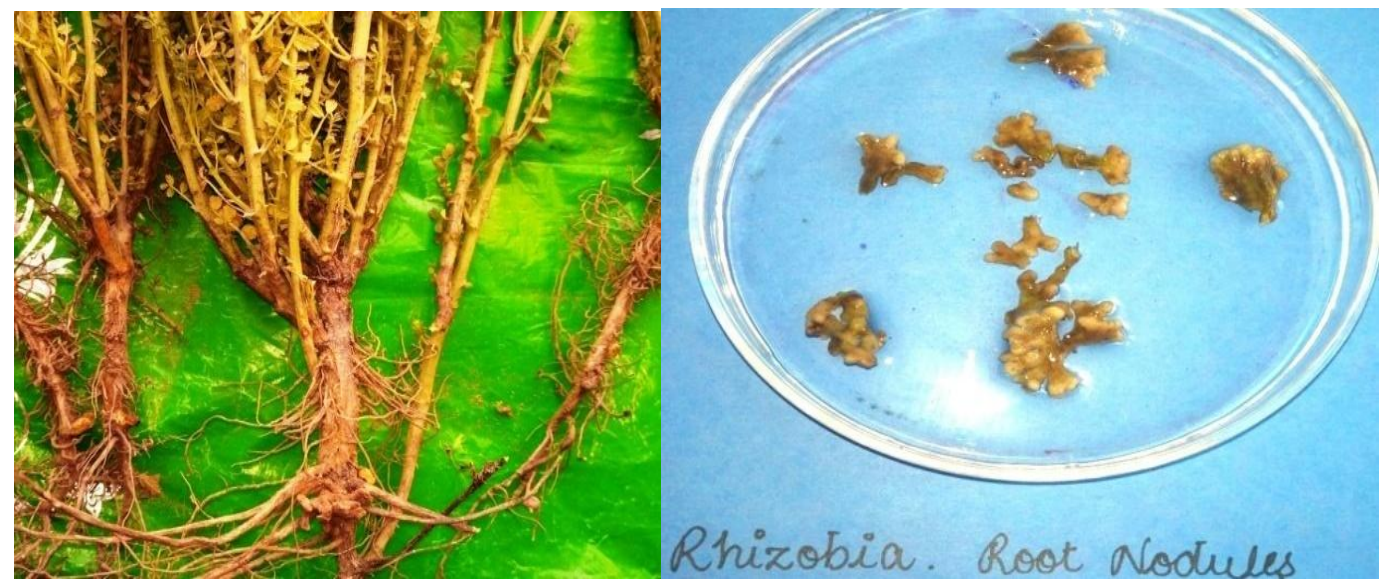

Fig.2 Isolated single colonies of rhizobia on CRYEMA plate

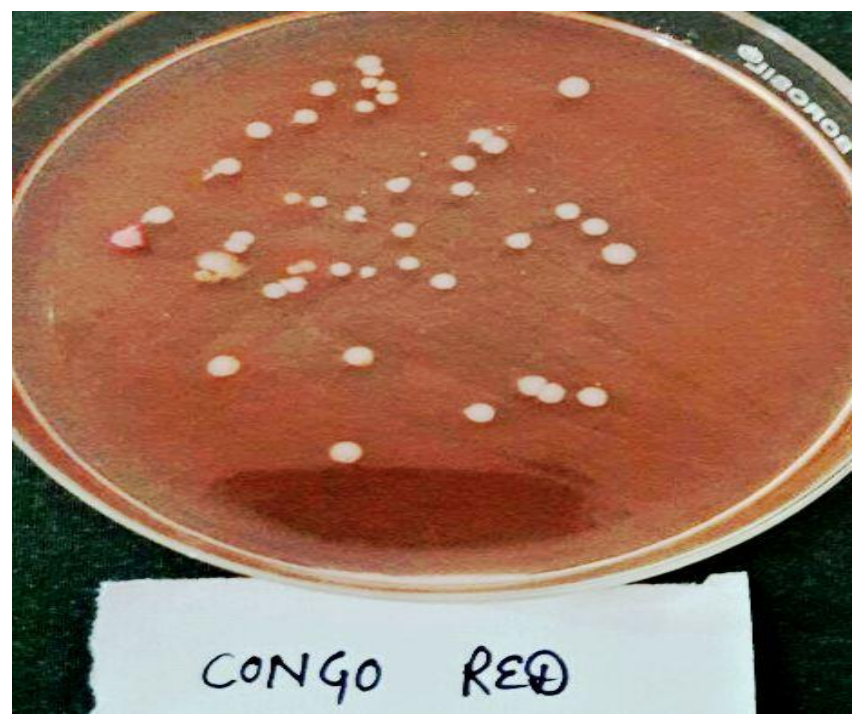

Fig.3 Effect of different concentration of $\mathrm{NaCl}$ on growth rate of Rhizobium

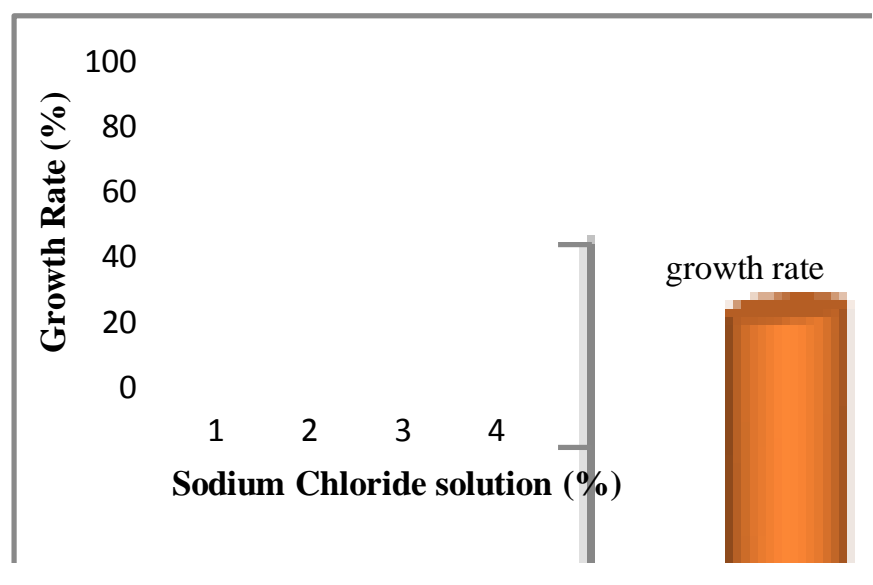


Fig.4 Effect of temperature on growth rateof Rhizobium

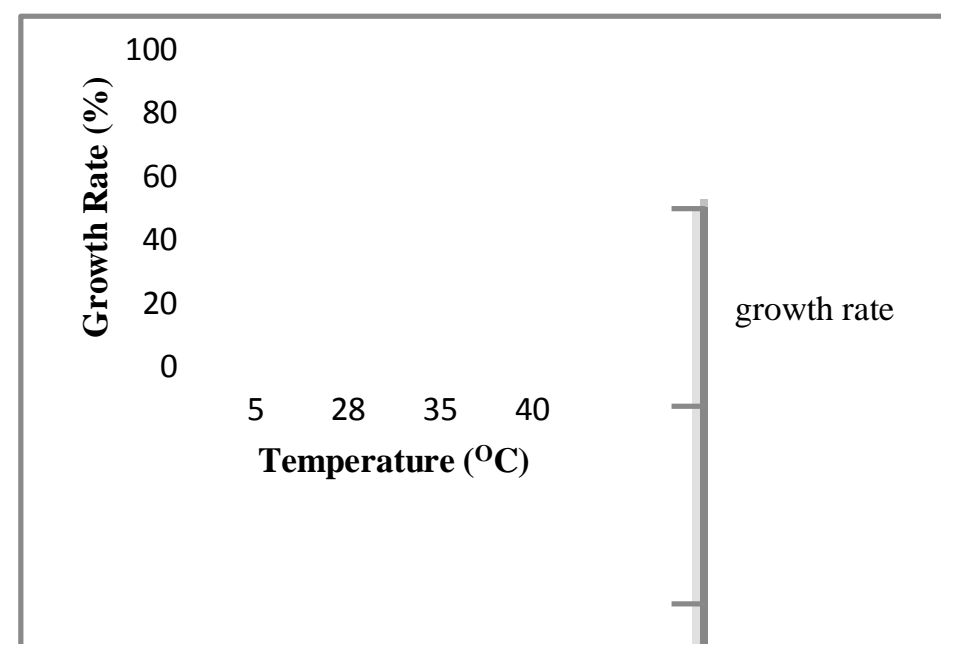

Fig.5 Effect of pH on growth rate of Rhizobium

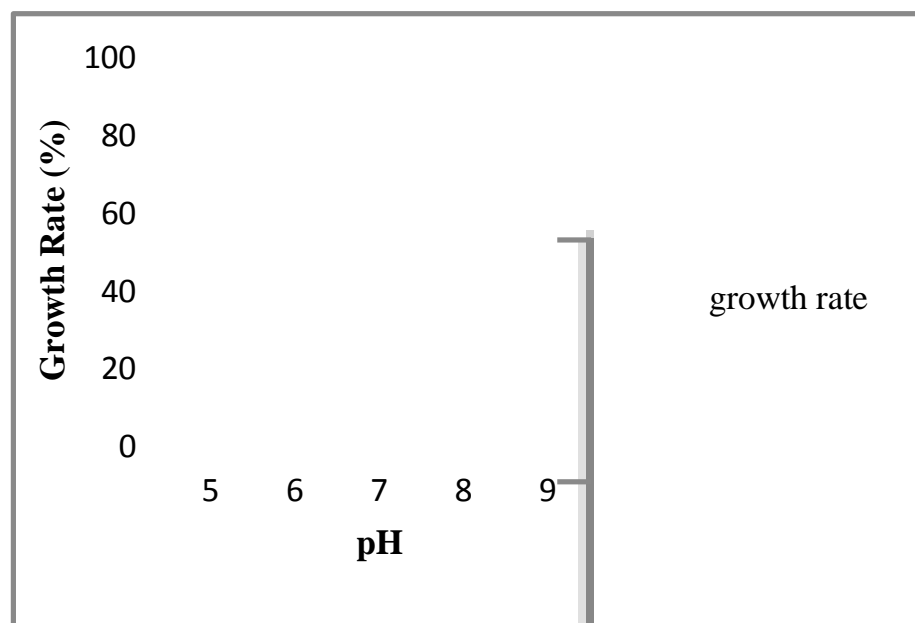

Fig.6 Effect of metal salts on growth of Rhizobium strain

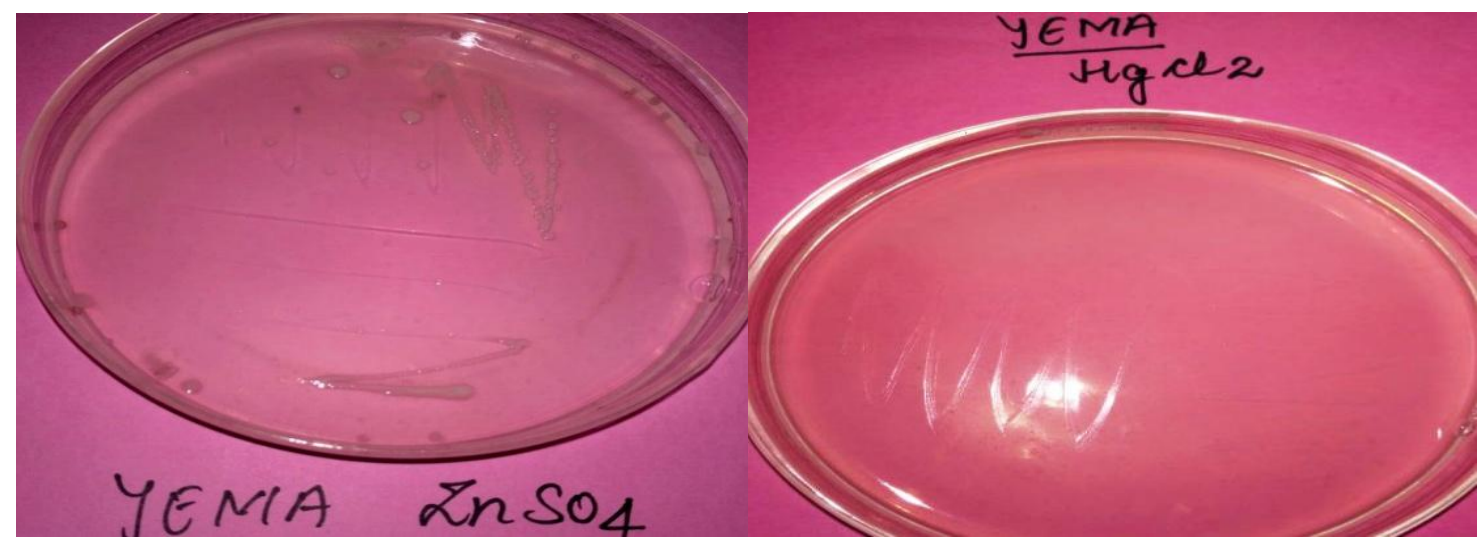


Fig.7 Effect of antibiotics on Rhizobium strain

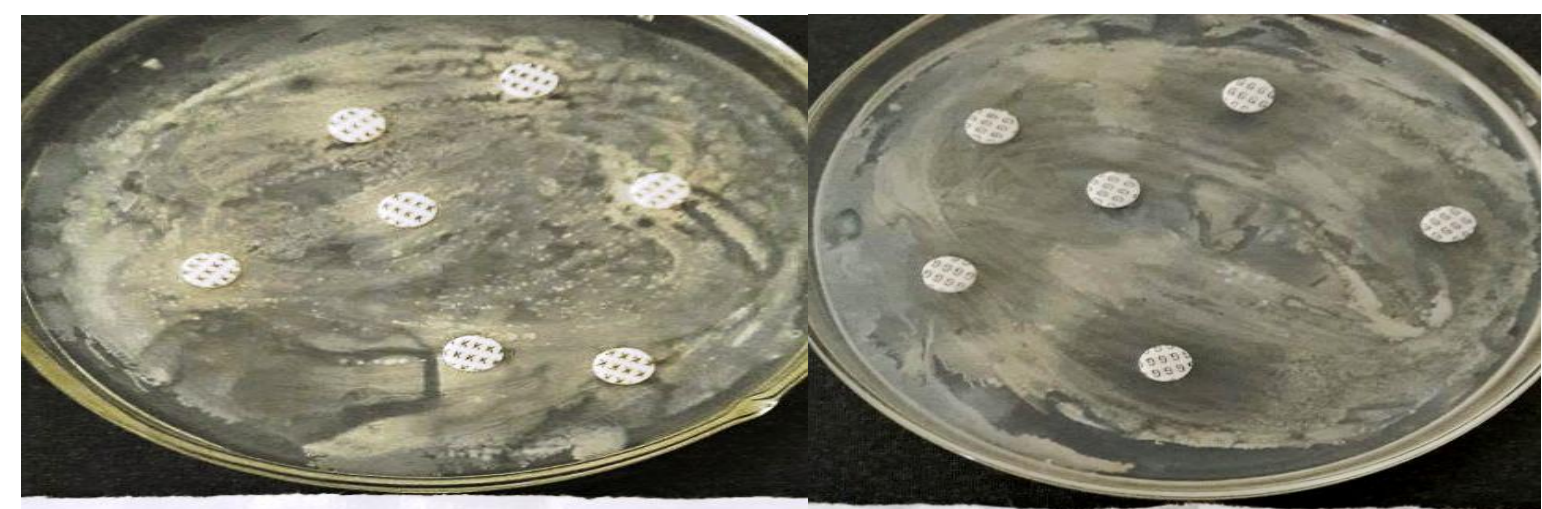

\section{Kanamycan Jesj Clenjamycan Jesy}
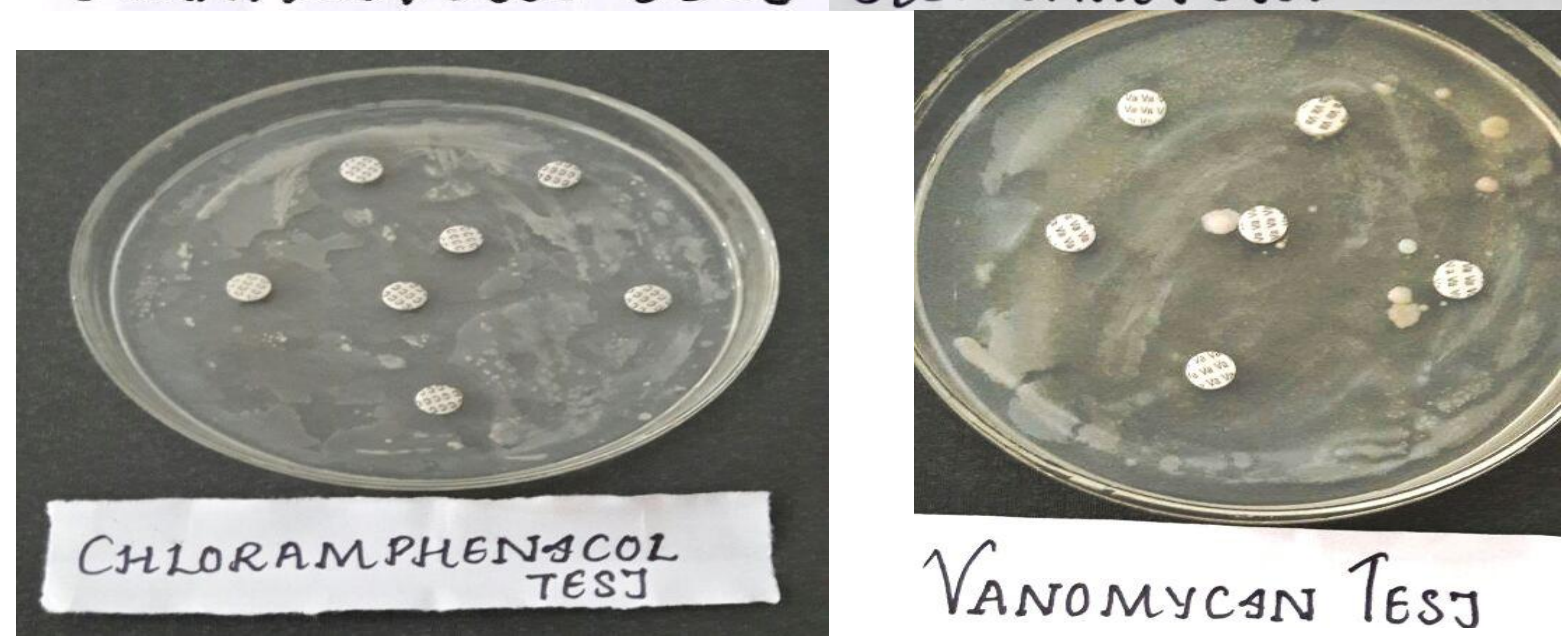

Fig.8 Effect of various biochemical test on Rhizobium growth
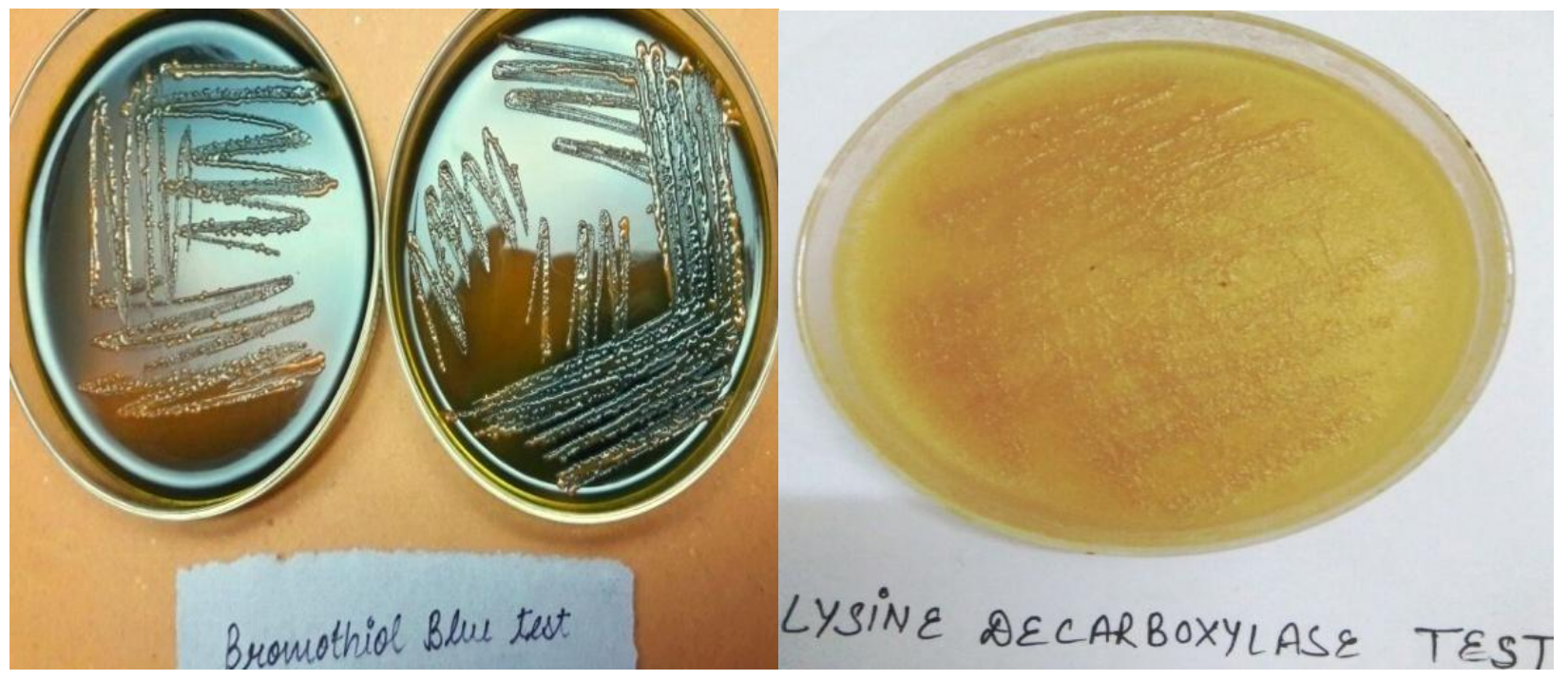


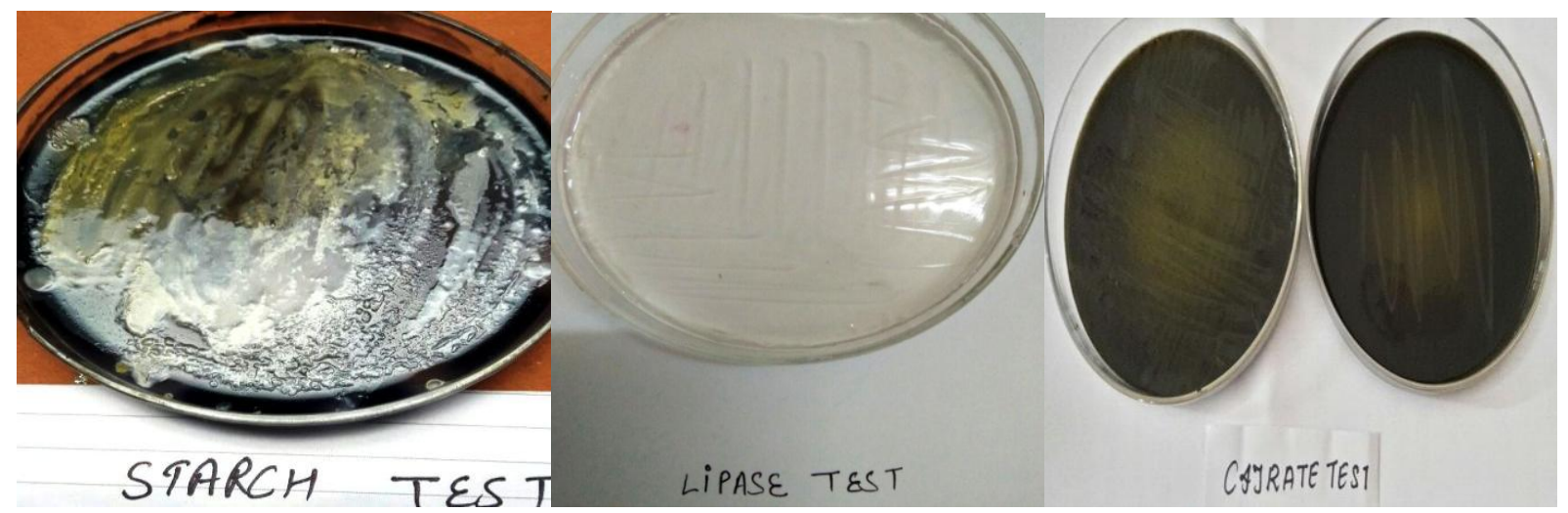

Fig.9 Effect of $\mathrm{NaCl}$ on growth of rhizobium

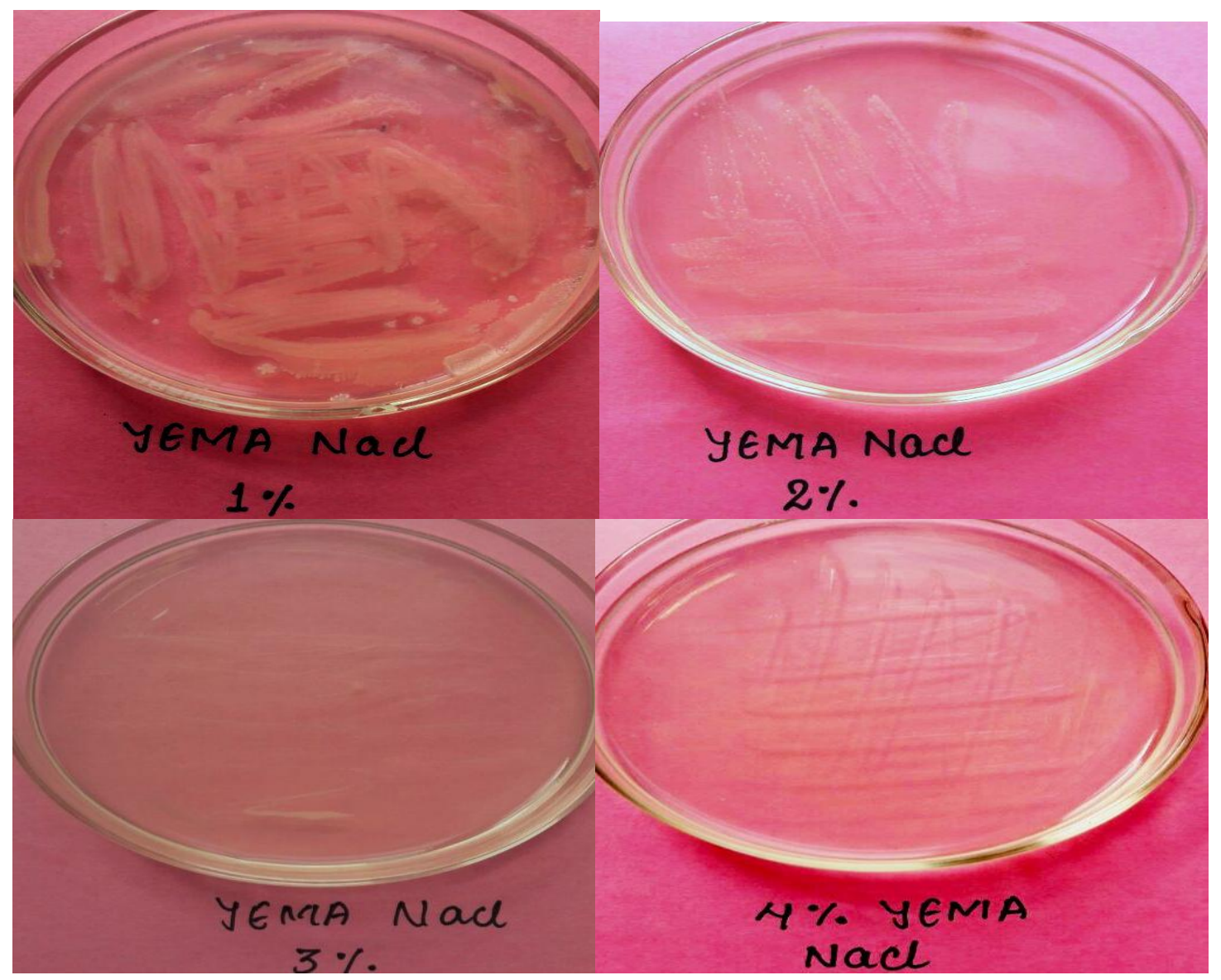

Effect of metal ions on growth of Rhizobia strain

Bacteria have developed controlled system to differentiate and cope up with harmful metal ions. Assessing the effect of metal salts on Rhizobia strains showed that all the strains were sensitive to mercuric chloride $\left(\mathrm{HgCl}_{2}\right)$.
On the other hand, $\mathrm{ZnSO}_{4}$ had least antibacterial effect at $0.1 \% \quad(\mathrm{w} / \mathrm{v})$ concentration. Most metal ions have to enter bacterial cells in order to produce physiological and toxic effect. Table 2, represents growth pattern of rhizobia strains towards effect of these metal ions i.e. $\mathrm{HgCl}_{2}$ and $\mathrm{ZnSO}_{4}$ (Fig. 6). Datta et al., 2015 
investigated the effect of metal ions on Rhizobium strains observed that all the strains were sensitive to mercuric chloride $\left(\mathrm{HgCl}_{2}\right)$. On the other hand, $\mathrm{ZnSO}_{4}$ and $\mathrm{CuSO}_{4}$ had minimum antibacterial effect at $0.1 \%(\mathrm{w} / \mathrm{v})$ and $1 \%(\mathrm{w} / \mathrm{v})$ concentration.

\section{Intrinsic Antibiotic Resistance (IAR) spectra}

An IAR spectrum is used for the identification of nodulating strains in reports intended to assess the ecological competitiveness. IAR test was carried out to identify isolates of Mesorhizobium sp. for sensitivity or resistance to various antibiotics. Test isolates were assessed against four antibiotics namely vancomycin, chloramphenicol, kanamycin and gentamycin. This estimation of intrinsic resistance to antibiotics revealed that the test isolates displayed high resistance to kanamycin and least resistance to chloramphenicol. The antibiotic resists the growth of Rhizobium. Antibiotic resistance pattern observed from tests was as follows kanamycin > gentamycin $>$ vancomycin $>$ chlora mphenicol (Fig. 7). Sharma et al., (2010) reported that most of the Rhizobium isolates were sensitive to chloramphenicol. Maatallah et al., 2002; Kucuk and Kivanc 2008 found great variation among chickpea rhizobia with respect to their IAR pattern. Gauri et al., 2012; Berrada et al., (2012) showed that the isolated strains of Rhizobium were highly resistant to kanamycin.

\section{Biochemical characterization}

Biochemical characterization of selected isolates was carried out on the basis of different biochemical tests viz., Oxidase, Catalase, Citrate utilization, Bromothymol blue, Lysine decarboxylase, Lipase and Caesinase test. In the present study, isolates were positive for oxidase and catalase, whereas negative for lipase, urease, caseinase test (Table 3; Fig. 8). On the basis of biochemical observations, isolates were designated as Mesorhizobium sp. Singh et al., (2013) also observed positive results for catalase and oxidase activities. Wani and Khan (2013) and Gauri et al., 2012, also reported that Mesorhizobium isolates were positive for catalase, oxidase and citrate utilization and were negative for lipase. Datta et al., 2015, observed that caseinase test is negative in Rhizobium leguminosarum strain. In our findings, the oxidase test showed positive where the colonies turned dark purple to black in color within 5 minutes in the test isolates. In the present study, catalase test was found to be positive due to bubble formation around bacterial colonies. Datta et al., 2015 also observed bubble formation around bacterial colonies of all four strains. Javed and Asghari et al., (2008) also characterized the Rhizobium from root nodule with the same biochemical tests.

In the present study, when test isolates were streaked on Bromothymol blue supplemented YEMA media for further confirmation. It was observed that growth occurs after 2 days of inoculation and turned YEM media from blue to yellow, confirming their nature as acid producers (Fig. 8; Table 3). Similarly, Datta et al., (2015) also observed that when all isolates were streaked on Bromothymol blue added YEMA medium, found after 2 days that growth turned YEM media from blue to yellow confirming their nature of being fast growers and acid producers. As no clear zone around the isolates was observed under starch hydrolysis assay which was performed to determine the production of reducing sugar from starch in bacteria. Similarly, Datta et al., (2015) also found that no clear zones around colonies were observed in Rhizobium leguminosarum (Fig. 8; Table 3). Lysine decarboxylase test was performed using bromocresol purple falkow media and no such color change in the medium. Datta et al., 2015 
showed change in the color of medium inoculated with Rhizobium phaseoli, Rhizobium trifolii and Bradyrhizobium japonicum but no such color change was found in the medium inoculated with Rhizobium leguminosarum.

In our findings use of citrate as a carbon source showed no color change, exhibiting negative citrate test (Fig. 8; Table 3). Datta et al., 2015 found that citrate utilization as a carbon source was positive in Rhizobium phaseoli and Rhizobium trifolii (the fast growing Rhizobia). However, slow growing Bradyrhizobium japonicum and Rhizobium leguminosarum showed no color change, exhibiting negative citrate test. From all the above findings and results confirms the presence of Rhizobium leguminosarum in our study.

Rhizobium is an important microorganism for the environment because of its nitrogen-fixing ability when in symbiotic relationship with plants (mainly legumes). This study confirmed that the root nodules of chickpea plants harbour the nitrogen-fixing bacteriumRhizobium. The present investigation seems to be promising approach to consider the optimum method for the isolation of rhizobia from chickpea plant that act as a potential candidate to be used in nitrogen fixation and lab based experiments. It also showed that these plants, when inoculated with Rhizobium isolates, perform better. This organism will greatly enhance agricultural production, if they are often used to inoculate legume plants, thereby reducing the environmental threat of synthetic nitrogen fertilizers. These findings allow us a new scope for extensive research in Agricultural Biotechnology.

\section{References}

Alexandre, A., Brígido C, Laranjo M, Rodrigues, S. and Oliveira, S. 2009.
Survey of chickpea rhizobia diversity in Portugal reveals the predominance of species distinct from Mesorhizobium cicero and Mesorhizobium mediterraneum. Microbiol Ecol.58, 930-41.

Bauer, A.W., Kirby, W.M, Sherris, J.C. and Turck, M. 1966. Antibiotic susceptibility testing by a standardized single disk method. Am J Clin Pathol. 45, 493-96.

Berrada, H., Nouioui, I., Houssaini, M.I., El Ghachtouli, N., Gtari, M. and Benbrahim, K.F. 2012. Phenotypic and genotypic characterizations of rhizobia isolated from root nodules of multiple legume species native of Fez, Morocco. Afr J Microbiol Res.6, 5314-24.

Biswas, J.C., Ladha, J.K., Dazzo, F.B., Yanni, Y.G. and Rolfe, B.G. 2000. Rhizobial inoculation influences seedling vigor and yield of rice. Agron J.92, 880-86.

Boboye, B.E., Ogundeji, B.A. and Evbohoin, H. 2011. Mutational search for high temperature $\left(60^{\circ} \mathrm{C}\right)$ tolerant variant of Rhizobium species CWP G34A. $A d v$ Biosci Biotechnol.2, 255-62.

Cheminingwa, G.N. and Vessey, J.K. 2006. The abundance and efficacy of Rhizobium leguminosarum bv. viciae in cultivated soils of eastern Canadian prairie. Soil Biol Biochem. 38, 294-302.

Collee, J.G. and Miles R.S. 1989. Mackie \& McCartney Practical Medical Microbiology. Churchill Livingstone, Edinburgh, 13th edn, pp-141-160.

Datta, A., Singh, R.K. and Kumar, S. 2015. Isolation, characterization and growth of Rhizobium strains under optimum conditions for effective biofertilizer production. Int. J. Pharm. Sci. Rev. Res. 32(1), 199-208.

Deora, G.S. and Singal, K. 2010. Isolation, biochemical characterization and preparation of biofertilizers using Rhizobium strain for commercial use. 
Biosci. Biotech. Res. Comm. 3(2), 132136.

Erman, M., Demir, S., Ocak, E., Tufenkci, S., Oguz, F. \& Akkopru, A. (2011). Effects of Rhizobium, arbuscular mycorrhiza and whey applications on some properties in chickpea (Cicer arietinum L.) under irrigated and rainfed conditions: Yield, yield components, nodulation and AMF colonization. Field Crops Res. 122(1), 14-24.

Garg, N. and Singla, R. 2009. Variability in the response of chickpea cultivars to short-term salinity, in terms of water retention capacity, membrane permeability and osmo-protection. Turk J Agric For. 33, 57-63.

Gaur, P.M., Tripathi, S., Gowda, C.L.L., Ranga Rao G.V., Sharma, H.C., Pande, S. and Sharma, M. 2010. Chickpea Seed Production Manual. Patancheru 502 324, Andhra Pradesh, India: International Crops Research Institute for the Semi-Arid Tropics. 28pp.

Gauri., Singh, A.K. andBamania, M. 2012. Characterization of Mesorhizobium sp. isolated from root nodules of Cicer arietinum. Int J Agri Sci Res.2, 142-154.

Javed, K. \& Asghari, B. (2008). Potential allelopathic effects of sunflowers on microorganisms. Afri. J. Biotech. 7(22), 4208-4211.

Jida, M.and Assefa, F. 2012. Phenotypic diversity and plant growth promoting characteristic of Mesorhizobium species isolated from chickpea (Cicer arietinum L.) growing areas Ethiopia. Afr $J$ Biotechnol.11, 7483-93.

Kantar, F., Hafeez, F.Y., Shivakumar, B.G., Sundaram, S.P., Tejera, N.A., Alsam, A., Bano, A. and Raja, P. 2007. Chickpea: Rhizobium management and nitrogen fixation. Chickpea Breed. Mgt. 179-192.

Kucuk, C. and Kivanc, M. 2008. Preliminary characterization of Rhizobium strains isolated from chickpea nodules. Afr $J$ Biotechnol. 7, 772-75.

Maatallah, J., Berraho, E.B., Munoz, S., Sanjuan, J. and Lluch, C. 2002. Phenotypic and molecular characterization of chickpea rhizobia isolated from different areas of Morocco. J Appl Microbiol.93, 531-40.

Niste, M., Vidican, R., Pop, R. and Rotar, I. 2013. Stress factors affecting symbiosis activity and nitrogen fixation by Rhizobium cultured in vitro. Pro Environ.6, 42-45.

Rai, R., Dash, P.K., Gaikwad, K. and Jain, P.K. 2013. Phenotypic and molecular profiling of indigenous chickpea rhizobia in India. CIBTech $J$ Microbiol.2, 33-38.

Roychowdhury, D., Paul, M. and Banerjee, S.K. 2015. Isolation identification and characterization of bacteria (Rhizobium) from chick pea (Cicer arietinum) and production of biofertilizer. Eur $J$ Biotech Biosci.3(12), 26-29.

Sadowsky, M. 2005. Soil stress factors influencing symbiotic nitrogen fixation. Nitrogen Fixation Agric Forestry Ecology Environ pp: 9-112.

Sharma, M.P., Srivastava, K. and Sharma, S.K. 2010. Biochemical characterization and metabolic diversity of soybean rhizobia isolated from Malwa region of Central India. Plant Soil Environ.56, 375-83.

Siddiqi, Z.A. and Mahmood, I. 2001. Effects of rhizobacteria and root symbionts on the reproduction of Meloidogyne javanicaand growth of chickpea. Bioresour. Technol. 79, 41-45.

Singh, N.P. and Sewak, S. 2013. Global perspective of chickpea research. AICRP on Chickpea. 8-13.

Singla, R. and Garg, N. 2005. Influence of salinity on growth and yield attributes in chickpea cultivars. Turk J Agric For.29, 231-35. 
Vanderlinde, E.M., Harrison, J.J., Muszynski, A., Carlson, R.W., Turner, R.J. and Yost, C.K. 2010. Identification of a novel $\mathrm{ABC}$ transporter required for desiccation tolerance, and biofilm formation in Rhizobium leguminosarum bv. Viciae. FEMS Microbiol Ecol.71, $327-40$.

Vessey, J.K. and Chemining'wa, G.N. (2006). The genetic diversity of Rhizobium leguminosarum bv. viciae in cultivated soils of the eastern Canadian prairie. Soil Biol. Biochem. 38, 153-163.

Vincent, J.M. 1970. A Manual for the Practical Study of Root-Nodule Bacteria, pp: 164 Blackwell Scientific Publications, Oxford.
Wani, P.A. and Khan, M.S. 2013. Isolation of multiple metal and antibiotic resistant Mesorhizobium sp. and their plant growth promoting activity. Research $J$ Microbiol, 8, 25-35.

Yadav, J., Verma, J.P. and Twari, N.K. 2010. Effect of plant growth promoting Rhizobacteria on seed germination and plant growth chickpea (Cicer arietnum L.) under in vitro conditions. Biol Furum Inter J.2, 15-18.

Zahran, H.H. 1999. Rhizobium-legume symbiosis and nitrogen fixation under severe conditions and in an arid climate. Microbiol Mol Biol Rev. 63(4), 968989.

\section{How to cite this article:}

Zeenat Wadhwa, Vivek Srivastava, Raj Rani, Tanvi, Kanchan Makkar and Sumit Jangra. 2017. Isolation and Characterization of Rhizobium from Chickpea (Cicer arietinum). Int.J.Curr.Microbiol.App.Sci. 6(11): 2880-2893. doi: https://doi.org/10.20546/ijcmas.2017.611.340 